\title{
PENGARUH PIJAT OKSITOSIN TERHADAP PRODUKSI ASI PADA PASIEN POST SECTIO SECARIA DI RS RAFFLESIA BENGKULU
}

\author{
The Influence of Oxytocosine Materials to Exclusive Breastfeeding Production \\ of Patient Post Sectio Caesarea in Rafflesia Hospital Bengkulu
}

\author{
Yeni Eliyanti ${ }^{1}$, Ema Herawati ${ }^{1}$ \\ ${ }^{1}$ Program Studi Keperawatan STIKES Bhakti Husada Bengkulu \\ Email : yenieliyanti@yahoo.co.id
}

\begin{abstract}
ABSTRAK
ASI merupakan makanan bayi yang kompleks dengan standar emas, yang mengandung zat gizi paling tepat, lengkap, dan selalu menyesuaikan dengan kebutuhan bayi setiap saat. Masalah dalam penelitian ini adalah banyak ibu yang mengeluh ASI nya tidak lancar keluar. Tujuan dari penelitian adalah untuk mempelajari pengaruh pijat oksitosin terhadap produksi asi ibu post sectio caesarea Di RSUD Kepahiang. Rancangan penelitian yang digunakan adalah one group pretest posttest. Populasi sebanyak 187 ibu dan pengambilan sampel dengan teknik total sampling yaitu sebanyak 15 ibu. Jenis data yang digunakan dalam penelitian adalah menggunakan data primer. Analisis data pada penelitian ini menggunakan analisis data univariat dan bivariat dengan metode statistik paired t test pada taraf signifikansi 0,05. Produksi ASI pasien post SC sebelum pijat oksitosin dengan nilai mean 16,80 Produksi ASI pasien post SC setelah pijat oksitosin dengan nilai mean 37,0. Ada adanya pengaruh pijat oksitosin terhadap produksi ASI pasien post sectio caesarea di RSUD Kepahiang dengan $p$ value = 0,000. Agar Petugas kesehatan khususnya Bidan selalu mempromosikan manfaat ASI dengan cara memberikan pelatihan atau mengajarkan kepada keluarga ibu postpartum teknik melakukan pijat oksitosin yang sangat banyak manfaatnya dalam pemberian ASI ekslusif.
\end{abstract}

Kata Kunci : pijat oksitosin, produksi ASI, pasien post SC

\begin{abstract}
Breast milk is a complex baby with a gold standard, which contains the most appropriate nutrients, complete, and always adjust to the needs of the baby at any time. The problem in this study was that many mothers who complain that her milk was not smooth out. The purpose of this research was to learn the effect of oxytocin massage on the production of mother ASI post sectio caesarea in RSUD Kepahiang. The research design used was one group pretest posttest. The population of 187 mothers and sampling with total sampling technique that was as many as 15 mothers. The type of data used in the study was primary data. Data analysis in this study used univariate and bivariate data analysis with paired test statistic at significance level 0,05. Breastfeeding production of post-SC patients before oxytocin massage with a mean value of 16.80. Breastmilk production of post-SC patients after oxytocin massage with a mean of 37.0. There was an effect of oxytocin massage on the production of post-sectio caesarea patients in RSUD Kepahiang with $p$ value 0.000. In order for health officers, especially Midwives always promote the benefits of breastfeeding by providing training or teaching to
\end{abstract}


the family of postpartum mothers techniques to massage the oxytocin is very much useful in exclusive breastfeeding.

Keywords: breast feeding milk production, oxytocyn massage, post SC patients

\section{A. Pendahuluan}

Angka kematian bayi di Indonesia berdasarkan hasil survei demografi dan kesehatan Indonesia (SDKI) SDKI 2012 memperlihatkan bahwa AKB sebesar 32 kematian per 1.000 kelahiran hidup, angka ini lebih rendah dibanding $\mathrm{AKB}$ yang direncanakan pada target MDG's yaitu 23 per 1.000 kelahiran hidup (Kemenkes, 2013). Siaran pers dari UNICEF menjelaskan bahwa kematian sekitar 30 ribu bayi Indonesia setiap tahunnya dapat dicegah melalui pemberian ASI secara eksklusif selama enam bulan sejak kelahiran bayi.

Angka kematian bayi di Indonesia berdasarkan hasil survei demografi dan kesehatan Indonesia (SDKI) SDKI 2012 memperlihatkan bahwa AKB sebesar 32 kematian per 1.000 kelahiran hidup, angka ini lebih rendah dibanding AKB yang direncanakan pada target MDG's yaitu 23 per 1.000 kelahiran hidup (Kemenkes, 2013). Siaran pers dari UNICEF menjelaskan bahwa kematian sekitar 30 ribu bayi Indonesia setiap tahunnya dapat dicegah melalui pemberian Air Susu Ibu (ASI) secara eksklusif selama enam bulan sejak kelahiran bayi. Pengetahuan para ibu di Indonesia terkait ASI diduga masih minim, akibatnya berdasarkan Riset Kesehatan Dasar (Riskesdas) 2013, angka cakupan ASI di Indonesia hanya 42 persen. Angka ini jelas di bawah target WHO yang mengharuskan cakupan ASI minimal 50 persen (UNICEF Indonesia, 2013).

World Health Organization (WHO) (2014), merekomendasikan agar setiap bayi baru lahir mendapatkan ASI eksklusif selama enam bulan, namun pada sebagian ibu tidak memberikan ASI eksklusif karena alasan ASInya tidak keluar atau hanya keluar sedikit sehingga tidak memenuhi kebutuhan bayinya. Secara umum target pencapaian ASI eksklusif untuk Indonesia mengalami kenaikan yang bermakna, namun pada beberapa keadaaan khusus, pemberian ASI Eksklusif tidak berlangsung secara sempurna dikarenakan adanya hambatan baik oleh karena ibu ataupun bayinya. Salah satu hambatan dalam pemberian ASI pada awal kehidupan seorang bayi adalah karena pengaruh tindakan Sectio caesarea.

Operasi Sectio caesarea mempunyai dampak tersendiri pada ibu antara lain tindakan anestesi, keadaan sepsis yang berat, mobilisasi terganggu, adanya tromboemboli, Activity of Dailing Living (ADL) terganggu, inisiasi menyusui dini ( IMD) tidak terpenuhi yang mengakibatkan masalah pada proses menyusui serta produksi ASI pada ibu (Purnama, 2013).

United Nations Chinden's Fund (UNICEF) menjelaskan bahwa sekitar 30 ribu kematian bayi Indonesia setiap tahunnya dapat dicegah dengan pemberian air susu ibu (ASI) secara eksklusif selama enam bulan sejak kelahiran bayi. Berdasarkan hasil Riset Kesehatan Dasar (Riskesdas) 2013, menerangkan bahwa angka cakupan ASI di Indonesia hanya 42\%. Angka ini jelas-jelas di bawah target rata-rata WHO yang mengharuskan target cakupan ASI minimal 50 persen pada setiap tahunnya untuk membantu penurunan angka kematian bayi (UNICEF Indonesia, 2013). 
ASI merupakan makanan bayi yang kompleks dengan standar emas, yang mengandung zat gizi paling tepat, lengkap, dan selalu menyesuaikan dengan kebutuhan bayi setiap saat sehingga ASI terbukti mempunyai keunggulan yang tidak dapat digantikan oleh makanan dan minuman apapun. Standar emas makanan bayi dimulai dengan tindakan Inisiasi Menyusu Dini (IMD), dilanjutkan dengan pemberian ASI secara eksklusif selama 6 (enam) bulan dan dapat diteruskan hingga 2 tahun kehidupan bayi (Gazali, 2008).

Beberapa ibu postpartum pada saat setelah melahirkan tidak langsung mengeluarkan ASI karena pengeluaran ASI merupakan suatu interaksi yang sangat komplek antara rangsangan mekanik, saraf dan bermacam macam hormon yang berpengaruh dalam proses pengeluaran oksitosin. Pengeluaran hormon oksitosin tidak hanya dipengaruh oleh isapan bayi saja tetapi juga dipengaruhi oleh reseptor yang terletak pada sistem duktus, bila duktus melebar atau menjadi lunak maka secara reflektoris dikeluarkanlah hormon oksitosin oleh hipofise yang memiliki peranan untuk memeras air susu dari alveoli (Muliani \& Rinawati, 2014).

Perlu adanya upaya membantu mengeluarkan ASI untuk beberapa ibu post partum. Dalam upaya pengeluaran ASI ada dua hal yang mempengaruhi yaitu produksi dan pengeluaran. Produksi ASI dipengaruhi oleh hormon prolaktin sedangkan pengeluaran ASI dipengaruhi oleh hormon oksitosin. Hormon oksitosin akan keluar melalui rangsangan keputing susu melalui isapan mulut bayi atau melalui pijatan tulang belakang ibu bayi, dengan melakukan pijatan pada tulang belakang ibu akan merasa tenang, rileks, meningkatkan ambang rasa nyeri, sehingga dengan begitu hormon oksitosin keluar dan ASI pun cepat keluar. (Endah, 2011).

Upaya untuk membantu pencapaian peran maternal pada wanita post partum dengan seksio sesarea, peran perawat maternitas sebagai pemberi asuhan utama dapat melakukan intervensi pijat punggung menggunakan aromaterapi lavender. Pijat punggung merupakan salah satu alternatif intervensi untuk membantu meningkatkan kelancaran produksi ASI. Pijat punggung adalah pemijatan pada sepanjang tulang belakang (vertebrae) dimulai dari batas bawah leher sampai tulang costae kelimakeenam dan merupakan usaha untuk merangsang pengeluaran hormon oksitosin setelah melahirkan (Biancuzzo, 2003; Indriyani, 2006; Yohmi \& Roesli, 2009). Back massage dilakukan untuk merangsang refleks oksitosin atau reflex let down melalui stimulasi sensori somatik dari sistem aferen.

Pijat oksitosin merupakan salah satu solusi untuk mengatasi ketidaklancaran produksi ASI. Pijat oksitosin adalah pemijatan pada sepanjang tulang belakang (vertebrae) sampai tulang costae kelima-keenam dan merupakan suatu usaha untuk merangsang hormon prolaktin dan oksitosin setelah melahirkan (Indriyani, 2006). Pijatan ini berfungsi untuk meningkatkan hormon oksitosin yang dapat menenangkan psikologi ibu yang tidak nyaman, sehingga ASI pun dapat keluar.

ASI adalah cairan kehidupan terbaik yang sangat dibutuhkan oleh bayi. ASI mengandung berbagai zat yang penting untuk tumbuh kembang bayi dan sesuai dengan kebutuhannya. ASI merupakan makanan yang terbaik yang dapat diberikan oleh seorang ibu kepada anak yang baru dilahirkan. 
Selain komposisinya sesuai untuk pertumbuhan dan perkembangan bayi yang berubah sesuai kebutuhan, ASI juga mengandung zat pelindung yang dapat menghindarkan bayi dari berbagai penyakit. Banyaknya manfaat dan pentingnya ASI, maka seorang ibu dan tenaga kesehatan harus memperhatikan kecukupan ASI pada bayi. Oleh karena itu, disini peran seorang ibu harus dipersiapkan sebaik mungkin pada proses laktasi baik pada masa prenatal maupun pada masa post natal. Salah satunya adalah melakukan perawatan payudara pada ibu nifas untuk memperlancar laktasi (Ambarwati \& Wulandari, 2008).

Permasalahan pengeluaran ASI dini bisa terjadi pada ibu yang mengalami proses persalinan melalui tindakan Sectio Caesaria (SC), hal ini dapat menimbulkan dampak buruk untuk kehidupan bayi padahal justru nilai gizi tertinggi ada dihari-hari pertama kehidupan bayi, yaitu kolostrum. Ibu dengan SC akan mengalami kesulitan inisiasi menyusui dini karena faktor rooming-in, kondisi sayatan pada perut ibu, kelemahan akibat pengaruh anestesi yang diberikan sebelumnya, oleh karena itu pasien dengan operasi Caesar baru bisa berhasil menyusui setelah lewat beberapa jam pasca melahirkan (Roesli, 2009).

Hasil penelitian yang pernah dilakukan di Indonesia terdapat beberapa metode yang dapat digunakan untuk membantu memperlancar produksi ASI pasca melahirkan diantaranya adalah metode Pijat Oksitosin, Teknik Marmet, Kompres Hangat, Massase Rolling (punggung), Breast Care, dan Metode SPEOS, tetapi karena keterbatasan informasi di layanan kesehatan tentang prosedur pelaksanaan maka metode- metode ini hanya dikenal saja tetapi jarang diberikan oleh perawat sebagai care giver kepada pasien.

Hasil studi pendahuluan yang dilakukan di RSUD Kepahiang terhadap 10 orang ibu yang melahirkan melalui tindakan SC, didapatkan $6 \mathrm{ibu}$ (60\%) menyatakan kurang lancarnya ASI sehingga tidak dapat memberikan ASI secara ekslusif, sedangkan 4 orang (40\%) ibu menyatakan produksi ASInya cukup dan lancar.

Rumusan masalah penelitian adalah "Apakah terdapat pengaruh pijat oksitosin terhadap produksi ASI pada pasien post sectio secaria di RS Rafflesia Bengkulu?'.Tujuan penelitian ini adalah untuk mempelajari pengaruh pijat oksitosin terhadap produksi ASI pada pasien post sectio secaria di RS Rafflesia Bengkulu.

\section{B. Metode Penelitian}

Penelitian ini telah dilaksanakan di RSUD Kepahiang pada Mei sampai dengan Juni 2017. Jenis penelitian yang digunakan pre-eksperimen atau eksperimen semu. Rancangan penelitian yang digunakan adalah one group pretest posttest (Sugiyono, 2013). Populasi dalam penelitian ini adalah ibu post $S C$ yang berada di RSUD Kepahiang berjumlah $187 \mathrm{ibu}$. Sampel dalam penelitian ini adalah pasien yang dilakukan SC sebanyak 15 ibu. Adapun teknik sampling pada penelitian ini adalah consecutive sampling. Jenis data yang dikumpulkan adalah data primer dan sekunder. Data tersebut mencakup pasien post SC dengan Instrumen yang digunakan untuk mengukur produksi ASI yaitu kemampuan ibu dalam memberikan ASI pada bayi. Data sekunder yaitu data yang diperoleh dari catatan pelaporan atau register RSUD Kepahiang meliputi data mengenai jumlah data yang akan diteliti, yaitu jumlah pasien post SC. Analisis ini 
digunakan untuk menilai produksi ASI post SC sebelum dan sesudah dilakukan pijat oksitosin dengan mengunakan paired $t$ test dengan program komputer for windows, sedangkan Confidental Interval (CI) yang digunakan adalah 95,0\%.

\section{Hasil Penelitian}

\section{Analisis Univariat}

Analisis ini dilakukan untuk mendapat gambaran distribusi frekuensi variabel independent (pijat oksitosin) dan variabel dependent (produksi ASI pasien Post SC).

Tabel 1

Rata-Rata Hasil Produksi ASI Ibu Post SC Sebelum Dilakukan Pijat Oksitosin di RSUD Kepahiang

\begin{tabular}{cccc}
\hline & Mean & Terendah & Tertinggi \\
\hline $\begin{array}{c}\text { Prduksi ASI } \\
\text { sebelum pijat } \\
\text { oksitosin }\end{array}$ & 16,80 & $10 \mathrm{cc}$ & $30 \mathrm{cc}$ \\
\hline
\end{tabular}

Berdasarkan Tabel $1 \mathrm{di}$ atas jumlah produksi pengeluaran ASI produksi ASI ibu post SC sebelum sebanyak $10 \mathrm{cc}$ dan paling banyak 30 dilakukan pijat oksitosin dengan cc..

Tabel 2

Rata-Rata Hasil Produksi ASI Ibu Post SC Setelah Dilakukan Pijat Oksitosin Di RSUD Kepahiang

\begin{tabular}{cccc}
\hline & Mean & Terendah & Tertinggi \\
\hline $\begin{array}{c}\text { Prduksi ASI setelah } \\
\text { pijat oksitosin }\end{array}$ & 37,00 & $25 \mathrm{cc}$ & $60 \mathrm{cc}$ \\
\hline
\end{tabular}

Berdasarkan Tabel 2, produksi ASI setelah dilakukan pemijatan oksitosin didapatkan jumlah produksi pengeluaran ASI sebanyak $25 \mathrm{cc}$ dan paling banyak $60 \mathrm{cc}$. Berdasarkan nilai mean di atas dikatakan bahwa terdapat perubahan secara deskriptif pada responden dengan dilakukannya pijat oksitosin.

Tabel. 3

Hasil Produksi ASI Ibu Post SC Sebelum Dan Setelah Dilakukan Pijat Oksitosin di RSUD Kepahiang

\begin{tabular}{cccc}
\hline & Mean & Standar Deviasi & Standard Error \\
\hline $\begin{array}{c}\text { Prduksi ASI Sebelum } \\
\text { Pijat Oksitosin }\end{array}$ & 16,80 & 5,735 & 1,481 \\
\hline $\begin{array}{c}\text { Produksi ASI Setelah } \\
\text { Pijat Oksitosin }\end{array}$ & 37,00 & 10,823 & 2,795 \\
\hline
\end{tabular}

Berdasarkan Tabel 3 di atas produksi ASI ibu post SC sebelum dilakukan pijat oksitosin dengan nilai mean 16,80 dan produksi ASI ibu post $S C$ sebelum dan setelah dilakukan pijat oksitosin menjadi mean 37,0. 
Berdasarkan nilai mean di atas dikatakan bahwa terdapat perubahan secara deskriptif pada responden dengan dilakukannya pijat oksitosin.

\section{Analisis Bivariat}

Analisis bivariat bertujuan untuk melihat pengaruh pijat oksitosin terhadap produksi ASI pada pasien post sectio secaria di RS Rafflesia Bengkulu.

Tabel. 4

Pengaruh Pijat Oksitosin Terhadap Produksi ASI Pasien Post Sectio Caesarea di RSUD Kepahiang

\begin{tabular}{|c|c|c|c|c|c|}
\hline $\begin{array}{c}\text { Produksi ASI pasien } \\
\text { post } S C\end{array}$ & Mean & SD & SE & $p$ value & $t_{\text {hitung }}$ \\
\hline Sebelum pijat oksitosin & 16,80 & 5,735 & 1,481 & \multirow{2}{*}{0,000} & \multirow{2}{*}{-11.496} \\
\hline Setelah pijat oksitosin & 37,00 & 10,823 & 2,795 & & \\
\hline
\end{tabular}

Berdasarkan Tabel 4 di atas diperoleh nilai mean produksi ASI pasien post SC sebelum pijat oksitosin adalah 16,80 dengan standar deviasi 5,735 , sedangkan setelah pijat oksitosin didapatkan nilai mean 37,0 dengan standar deviasi 10,823, maka didapatkan perbedaan antara nilai mean sebelum dan setelah adalah 20,2 dengan standar deviasi 5,088. Berdasarkan hasil uji statistik didapatkan nilai $p=0,000$, berarti < $0,05(\alpha)$ sehingga dapat disimpulkan bahwa adanya pengaruh pijat oksitosin terhadap produksi asi pasien post sectio caesarea di RSUD Kepahiang.

\section{Pembahasan}

Produksi ASI setelah dilakukan pemijatan oksitosin meningkat dibandingkan dengan sebelum dilakukan pemijatan oksitosin. Pijat oksitosin dilakukan pada tulang belakang mulai dari costa ke 5-6 sampai scapula, neurotransmitter akan merangsang medulla oblongata langsung mengirim pesan ke hypothalamus di hypofise posterior untuk mengeluarkan oksitosin sehingga menyebabkan buah dada mengeluarkan air susu nya (Gustriani, 2015). Pijat oksitosin dilakukan selama 15 menit minimal sehari sekali yang bertujuan untuk merangsang refleks oksitosin atau reflex let down yaitu rangsangan isapan bayi melalui serabut saraf, memacu hipofise bagian belakang untuk mensekresi hormon oksitosin ke dalam darah. Oksitosin ini menyebabkan sel-sel myopytel yang mengelilingi alveoli dan duktuli berkontraksi, sehingga ASI mengalir dari alveoli ke duktuli menuju sinus dan puting. Dengan demikian sering menyusu baik dan penting untuk pengosongan payudara agar tidak terjadi engorgement (pembengkakan payudara), tetapi sebaliknya memperlancar pengeluaran ASI (Pinem, 2012).

Melalui pijatan atau rangsangan pada tulang belakang, neurotransmitter akan merangsang medulla oblongata langsung mengirim pesan ke hypothalamus di hypofise posterior untuk mengeluarkan oksitosin yang menyebabkan buah dada mengeluarkan air susunya. Dengan pijatan di daerah tulang belakang ini juga akan mereklaksasi ketegangan dan menghilangkan stress dan dengan begitu hormon oksitosin keluar dan akan membantu pengeluaran air susu ibu, dibantu dengan isapan bayi pada 
putting susu pada saat segera setelah bayi lahir dengan keadaan bayi normal (Guyton, 2012).

Secara fisiologis pijat oksitosin merangsang refleks oksitosin atau letdown untuk mensekresi hormon oksitosin ke dalam darah. Oksitosin ini menyebabkan sel- sel miopitelium disekitar alveoli berkontraksi dan membuat ASI mengalir dari alveoli ke duktuli menuju sinus dan putting kemudian dihisap oleh bayi. Semakin lancar pengeluaran ASI semakin banyak pula produksi ASI (Wijayanti \& Warsiti, 2014).

Hal tersebut sesuai dengan pendapat Mardiyaningsih (2010) bahwa produksi ASI sangat dipengaruhi oleh hormon prolaktin yang akan memproduksi ASI, dan hormon oksitosin yang berpengaruh pada kelancaran pengeluaran ASI, karena semakin ASI keluar produksi ASI akan semakin meningkat.

Laktasi melibatkan proses produksi dan pengeluaran ASI. Produksi ASI sudah dimulai sejak kehamilan, dan pengeluaran ASI masih dihambat selama masa kehamilan. Segera setelah bayi dan placenta lahir, estrogen dan progesterone turun drastis sehingga kerja prolaktin dan okstosin akan maksimal sehingga pengeluaran dan pengeluaran ASI akan lancar. Tidak keluarnya ASI tidak semata karena produksi ASI tidak ada atau tidak mencukupi, tetapi sering kali produksi ASI cukup namun pengeluarannya yang dihambat akibat hambatan sekresi oksitosin.

Pijat oksitosin ini dilakukan untuk merangsang refleks oksitosin atau refleks let down, dilakukan dengan cara memijat pada daerah punggung sepanjang kedua sisi tulang belakang sehingga diharapkan dengan dilakukan pemijatan ini, ibu akan merasa rileks dan kelelahan setelah melahirkan akan hilang. Jika ibu rileks dan tidak kelelahan setelah melahirkan dapat membantu merangsang pengeluaran hormon oksitosin (Depkes RI, 2007).

Pijat oksitosin bermanfaat untuk meningkatkan gerakan ASI ke payudara, menambah pengisian ASI ke payudara, dan memperlancar pengeluaran ASI. Menurut Nugroho et al. (2011), produksi dan pengeluaran ASI dimulai pada tahap laktogenesis II, penanda biokimiawi mengindikasikan bahwa proses laktogenesis II dimulai sekitar 30-40 jam setelah melahirkan, tetapi biasanya para ibu baru merasakan payudara penuh sekitar 5073 jam (2-3 hari) setelah melahirkan.

Peneliti dapat menyimpulkan bahwa sebagian besar ibu nifas merasakan manfaat pijat oksitosin dimana produksi ASI sebelum dilakukan pijat oksitosin menjadi lancar setelah dilakukan pijat oksitosin.Hal ini juga membuat ibu merasa rileks, lebih nyaman, dan kelelahan setelah melahirkan juga berkurang.

Hasil penelitian menunjukkan adanya pengaruh pijat oksitosin terhadap pengeluaran ASI. Hal ini dikarenakan pijat oksitosin merupakan tindakan yang dilakukan pada ibu menyusui yang berupa back massage pada punggung ibu untuk meningkatkan pengeluaran hormon oksitosin. Pijat oksitosin yang dilakukan akan memberikan kenyamanan pada ibu sehingga akan memberikan kenyamanan pada bayi yang disusui. Secara fisiologis hal tersebut meningkatkan hormon oksitosin yang dikirimkan ke otak sehingga hormon oksitosin dikeluarkan dan mengalir ke dalam darah, kemudian masuk ke payudara Mama menyebabkan otot-otot di sekitar alveoli berkontraksi dan membuat ASI mengalir di saluran ASI (milk ducts). 
Hormon oksitosin juga membuat saluran ASI (milk ducts) lebih lebar, membuat ASI mengalir lebih mudah.

Hal ini dibuktikan bahwa semua ibu postpartum di ruamg kebidanan berada satu ruang dengan bayinya (rooming in) sehingga bayi dapat di berikan ASI sewaktu waktu jika bayi menginginkan dan semua petugas kesehatan menganjurkan ibu untuk selalu memberi ASI ekslusif. Hal ini sesuai dengan Peraturan Pemerintah no 33 tahun 2012 yang menyebutkan bahwa tenaga kesehatan dan penyelenggara fasilitas pelayanan kesehatan wajib melakukan inisiasi menyusu dini terhadap bayi yang baru lahir kepada ibunya paling singkat selama 1(satu) jam dan pasal 10 menyebutkan Tenaga kesehatan dan penyelenggara fasilitas pelayanan kesehatan wajib menempatkan ibu dan bayi dalam 1 (satu) ruangan atau rawat gabung kecuali atas indikasi medis yang di tetapkan oleh dokter. Dengan demikian maka pijat oksitosin mempengaruhi produksi ASI.

Fenomena yang ditemukan di lapangan bahwa produksi dan ejeksi ASI yang sedikit pada hari-hari pertama setelah melahirkan menjadi kendala dalam pemberian ASI secara dini. Penurunan produksi ASI pada hari-hari pertama setelah melahirkan dapat disebabkan olehkurangnya rangsangan hormon prolaktin dan oksitosin yang sangat berperan dalam kelancaran produksi ASI. Kondisi ini dialami juga oleh ibu yang melahirkan dengan seksio sesarea. Hal ini disebabkan karena penggunaan obatobatan yang digunakan pada saat operasi maupun sesudah operasi.

Bila bayi tidak mendapatkan cukup ASI, maka bayi akan sering menangis, menyusu lebih lama dari frekuensi biasanya, dan ingin selalu minum ASI dengan waktu yang cukup pendek. Hal ini berlawanan dengan hasil penelitian ini karena pada penelitian ini didapatkan hasil bahwa frekuensi bayi minum ASI pada waktu lahir adalah 8 kali yang meningkat pada minggu pertama dan kedua. Teori menyatakan bahwa bila bayi cukup mendapatkan nutrisi, maka rata rata frekuensi menyusu bayi antara 8-12 kali dan bayi akan tidur tenang/nyenyak 2-3 jam setelah menyusu. Hal ini menunjukkan bahwa bila bayi menyusu semakin sering, maka ASI yang di produksi semakin banyak karena semakin tinggi kadar oksitosin pada peredaran darah yang akan merangsang prolaktin untuk terus memproduksi ASI (Roesli, 2008).

Hasil penelitian ini sejalan dengan penelitian yang dilakukan oleh Mardiyaningsih di wilayah Jawa Tengah pada tahun 2010. Pada analisa data menggunakan chi square terhadap ibu postpartum sectio sesaria dengan pemberian intervensi kombinasi teknik Marmet dan pijat oksitoksin dengan jumlah sampel sebanyak 27, sebanyak $22(81,5 \%)$ ibu produksi ASInya lancar sementara terdapat $11(40.7 \%)$ saja pada ibu kelompok kontrol yang produksi ASInya lancar. Pada analisa data terlihat nilai $\mathrm{p}$ value $=0,005$ dan OR 6,400 (CI 1,856-22,068) sehingga dapat dikatakan bahwa ibu post SC yang diberikan intervensi kombinasi teknik marmet dan pijat oksitoksin berpeluang 6 kali le bih besar memiliki produksi ASI lancar dibandingkan kelompok kontrol.

Didukung oleh penelitian sebelumnya yang dilakukan oleh Suryani \& Astuti (2013) dengan judul penelitian "Pengaruh Pijat Oksitosin Terhadap Produksi ASI Ibu Postpartum Di BPM Wilayah Kabupaten Klaten", bahwasanya dari hasil penelitian ada pengaruh pijat oksitosin terhadap produksi ASI ibu postpartum dengan $\mathrm{p}$ 
value $=0,001(<0,05)$. Selanjutnya dari hasil penelitian Wijayanti \& Warsiti (2014) yang berjudul Pengaruh Pijat Oksitosin Terhadap Produksi ASI Pada Ibu Postpartum Di Puskesmas Mergangsan Yogyakarta Tahun 2014" menunjukkan bahwa ibu nifas mengalami peningkatan produksi ASI setelah dilakukan pijat oksitosin terlihat dari $\mathrm{p}$ value $=0,032 \quad(<0,05)$ yang berarti ada pengaruh pijat oksitosin terhadap produksi ASI pada ibu nifas.

\section{Daftar Pustaka}

Ambarwati \& Wulandari. (2009). Asuhan Kebidanan Nifas. Jogjakarta: Mitra Cendikia offset.

Biancuzzo, M. (2003). Breastfeeding The Newborn: Clinical Strategies For Nurses. 1 st edition St. Louis Missouri: Mosby Inc.

Depkes RI. (2007). Panduan Manajemen Laktasi: Diit Gizi Masyarakat. Jakarta: Depkes RI.

Endah, S. N. \& Masdinarsah, I. (2011). Pengaruh Pijat Oksitosin terhadap Pengeluaran Kolostrum pada Ibu Post Partum di Ruang Kebidanan Rumah Sakit Muhammadiyah Bandung. Jurnal Kesehatan Kartika, 1-9. Diunduh dari : http://www.stikesayani.ac.id/pu blikasi/ejournal/filesx/2011/201112/201 112-001.pdf.

Gazali, (2008). Hubungan Status Gizi dengan Klasifikasi Pneumonia pada Anak Usia 6 Bulan - 5 Tahun di Puskesmas Gilingan Kecamatan Banjarsari Surakarta. [Skripsi]. Surakarta: Universitas Sebelas Maret.

Gustriani, N. (2015). Pengaruh Pijat Oksitosin terhadap Pengeluaran
ASI pada Pasien Post Seksio Sesarea di Ruangan Nifas Rumah Sakit Wilayah Makassar. Tesis. Universitas Hasanuddin.

Guyton. (2012). Buku Ajar Fisiologi Kedokteran. Edisi 9. Jakarta: EGC.

Indriyani, S. (2006). Pengaruh Menyusui Dini dan Teratur Terhadap Produksi ASI Pada Ibu Post Partum dengan Sectio Caesarea di RSUD Dr. Soebandi Jember dan Dr. H. Koesnadi Bondowoso. Depok: FIK UI.

Mardiyaningsih, E. (2010). Efektifitas Kombinasi teknik marmet dan pijt oksitosin terhadap Produksi asi ibu post sectoin caesare di rumah sakit wilayah jawa tengah. Depok: FIK UI.

Muliani, S.N. \& Rinawati M. (2014). Keluarga Berencana dan Alat Kontrasepsi. Yogyakarta: Nuha Medika.

Nugroho T, Nurrezki, Desi, W., \& Wilis (2011). Buku Ajar Asuhan Kebidanan Nifas (Askeb 3). Yogyakarta: Nuha Medika.

Pinem. (2012). Hubungan Pengetahuan Ibu Meyusui dengan Pemberian ASI Eksklusif di Kelurahan Sei Sikambing Medan Tahun 2012. Skripsi : Bidan Pendidik USU. Diunduh dari http://repository.usu.ac.id/handl e/123456789/49107.

Purnama, U. (2013). Hubungan dntara Status Ibu Bekerja dan Tidak Bekerja dengan Status Gizi Anak Balita di Kecamatan Medan Tembung. Sumatra Utara : USU Press.

Roesli, U. (2009). Mengenal ASI Eksklusif. Cetakan pertama. Jakarta: Trubus Agriwidya. 
Roesli, U., \& Yohmi, E. (2009). Manajemen laktasi. Jakarta: IDAI.

Sugiyono. (2013). Metode Penelitian Kualitatif-Kuantitatif dan RND, Bandung : Alfabeta.

Suryani., E. \& Astuti, E. W. (2013). Pengaruh Pijat Oksitosin Terhadap Produksi Asi Ibu Post Partum di BPM Wilayah Kabupaten Klaten. Jurnal Terpadu Ilmu Kesehatan, 2 (2) : 123-128. Diunduh dari : http://jurnal.poltekkessolo.ac.id/index.php/Int/article/ viewFile/69/59.

UNICEF Indonesia, (2013). ASI Eksklusif Tekan Angka Kematian Bayi Indonesia.
Diunduh dari : http://situs.kesrepro.info/kia/ag u/2006/kia03.htm

WHO. (2014). Sustainable Development Goal's. In: Station $U$, editor. Jakarta: United Nations

Wijayanti. L. \& Warsiti. (2014). Pengaruh Pijat Oksitosin Terhadap Produksi ASI pada Ibu Postpartum di Puskesmas Mergangsan Yogyakarta tahun 2014. [Skripsi]. Program Studi Bidan Pendidik STIKES Aisyiyah Yogyakarta. Diunduh dari

http://digilib.unisayogya.ac.id/1 $\underline{076 / .}$ 